\title{
Characterization of Susceptibility and Resistance Responses to Potato Cyst Nematode (Globodera spp.) Infection of Tomato Lines in the Absence and Presence of the Broad-Spectrum Nematode Resistance Hero Gene
}

\author{
Miroslaw Sobczak, ${ }^{1,2}$ Anna Avrova, ${ }^{1}$ Justyna Jupowicz, ${ }^{2}$ Mark S. Phillips, ${ }^{1}$ Karin Ernst, ${ }^{3}$ Amar Kumar ${ }^{1}$ \\ ${ }^{1}$ Plant Pathogen Interactions Programme, Scottish Crop Research Institute, Invergowrie, Dundee, DD2 5DA, U.K.; \\ 2Permanent address: Department of Botany, Warsaw Agricultural University (SGGW), Nowoursynowska 159, Building 37, \\ 02-776, Warsaw, Poland; ${ }^{3}$ Institut für Entwicklungs- und Molekularbiologie der Pflanzen, Heinrich-Heine-Universität \\ Düsseldorf, D-40225 Düsseldorf, Germany
}

Submitted 6 July 2004. Accepted 20 October 2004.

\begin{abstract}
The tomato Hero $A$ gene is the only member of a multigene family that confers a high level $(>80 \%)$ of resistance to all the economically important pathotypes of potato cyst nematode (PCN) species Globodera rostochiensis and G. pallida. Although the resistance levels of transgenic tomato lines were similar to those of the tomato line LA1792 containing the introgressed Hero multigene family, transgenic potato plants expressing the tomato Hero $A$ gene are not resistant to PCNs. Comparative microscopy studies of in vitro infected roots of PCN-susceptible tomato cv. Money Maker, the resistant breeding line LA1792, and transgenic line L10 with Ro1 pathotype have revealed no statistically significant difference in the number of juveniles invading roots. However, syncytia (specialized feeding cells) induced in LA1792 and L10 roots mostly were found to have degenerated a few days after their induction, and a few surviving syncytia were able to support only the development of males rather than females. Thus, the ratio between males and females was biased towards males on LA1792 and L10 roots. A series of changes occur in resistant plants leading to formation of a layer of necrotic cells separating the syncytium from stellar conductive tissues and this is followed by degradation of the syncytium. Although the Hero $A$ gene is expressed in all tissues, including roots, stems, leaves, and flower buds, its expression is upregulated in roots in response to $\mathrm{PCN}$ infection. Moreover, the expression profiles of the Hero A correlates with the timing of death of the syncytium.
\end{abstract}

Additional keywords: genetic transformation, plant-parasite nematodes, sexual generations.

The potato cyst nematodes (PCNs) Globodera rostochiensis and $G$. pallida are major pests of potato throughout Europe and worldwide in temperate climates (Brodie et al. 1998). These plant-parasite nematodes have a complex developmental

Corresponding author: A. Kumar;

Fax: ++ 441382 562426; E-mail: akumar@scri.sari.ac.uk

M. Sobczak and A. Avrova contributed equally to the work.

*The $\boldsymbol{e}$-Xtra logo stands for "electronic extra" and indicates that Figure 2 appears in color online. cycle consisting of four juvenile stages and a generation of adult males and females (Sijmons et al. 1994). They are obligatory biotrophs whose reproductive success depends on the establishment of a feeding site within host plant roots. PCNs modify plant morphological and physiological processes to induce a specialized feeding structure called a "syncytium" within the host roots. Features of syncytium formation include DNA endoduplication, the absence of central vacuoles, an increase in organelle numbers, formation of cell wall ingrowths, and partial cell wall dissolution to allow cellular fusion. Thus, a syncytium is a multinucleate transfer cell that functions as a metabolic sink that delivers nutrients to the developing nematode (Golinowski et al. 1996; Jones and Northcote 1972).

PCNs and similar cyst-forming nematodes usually are able to invade and develop on resistant plants, but their reproduction is severely compromised. The first differences between resistant and susceptible responses appear after root invasion by second-stage juveniles (J2). There are two basic defense mechanisms against sedentary nematodes. The first is a hypersensitive response (HR), when the invading juvenile is not able to induce a feeding site and becomes surrounded and embedded among necrotized cells. This mechanism, which is common against root-knot nematodes (Meloidogyne spp.) (BleveZacheo et al. 1998; Paulson and Webster 1972), has not been observed for PCNs. The second mechanism, often described as a "hypersensitive-like" or "delayed hypersensitive" response, is observed following PCN infection (e.g., Globodera spp.) in resistant plants. It appears after syncytium induction and leads to slow deterioration or abnormal development of the feeding site (Grymaszewska and Golinowski 1998; Holtmann et al. 2000; Rice et al. 1985; Wyss et al. 1984).

In agricultural practice, nematodes are controlled by crop rotation and use of nematicides and resistant cultivars. Only a few natural major resistance genes to the PCN have been identified within potato cultivars and in some related Solanum spp., but none of them as individuals can confer resistance to both Globodera spp. (Phillips 1994). However, the recent emergence of G. pallida as a major pathogen in the U.K. potato crop due to the persistent use of potato cultivars resistant to $G$. rostochiensis has necessitated the development of potato cultivars possessing resistance to both PCN species. Interestingly, a broad-spectrum nematode resistance gene, called Hero, has 
been identified in a wild tomato (Lycopersicon pimpinellifolium) that confers a high level of resistance (>80\%) against all pathotypes of $G$. rostochiensis (Ellis and Maxon-Smith 1971; Ganal et al. 1995). In the early 1970s, the Hero gene initially was identified as a major nematode resistance gene to $G$. rostochiensis pathotype Ro1 and was used to introgress resistance into cultivated tomato (Ellis and Maxon-Smith 1971). Recently, the Hero A gene has been cloned by map-based cloning and complementation (Ernst et al. 2002). The Hero A gene belongs to a multigene family and is a member of the coiledcoil nucleotide binding site (NBS) leucine-rich repeat (LRR) class of resistance genes. Furthermore, it was shown that transgenic tomato lines of PCN-susceptible $L$. esculentum cv. Money Maker expressing the Hero A gene were resistant to all pathotypes of $G$. rostochiensis and were partially resistant to G. pallida pathotype $\mathrm{Pa} 2 / 3$. Thus, the Hero A gene potentially is an economically important nematode resistance source for tomato and potato breeding.

Apart from the Hero A gene, four additional nematode resistance genes have been isolated: the wild beet (Beta procumbens) $H_{s} 1^{\text {pro-1 }}$ gene for cyst nematode Heterodera schachtii (Cai et al. 1997), the tomato Mi-1.2 gene for Meloidogyne spp. (Milligan et al. 1998; Vos et al. 1998), the potato Gpa2 gene for $G$. pallida (van der Vossen et al. 2000), and the potato Grol-4 gene for G. rostochiensis Rol (Paal et al. 2004). However, only the $M i-1.2$ gene has been characterized comprehensively at the cellular and molecular levels (Branch et al. 2004; Hwang and Williamson 2003; Hwang et al. 2000). Here we provide a detailed characterization of susceptibility and resistance responses to PCNs at cellular and molecular levels in tomato lines with or without the Hero gene. Furthermore, a comparative study of the Hero gene-mediated resistance responses between a conventionally produced resistant line LA1792 (possessing the complete cluster of Hero genes in a PCN-susceptible Alisa Craig background) and a transgenically pro-

A
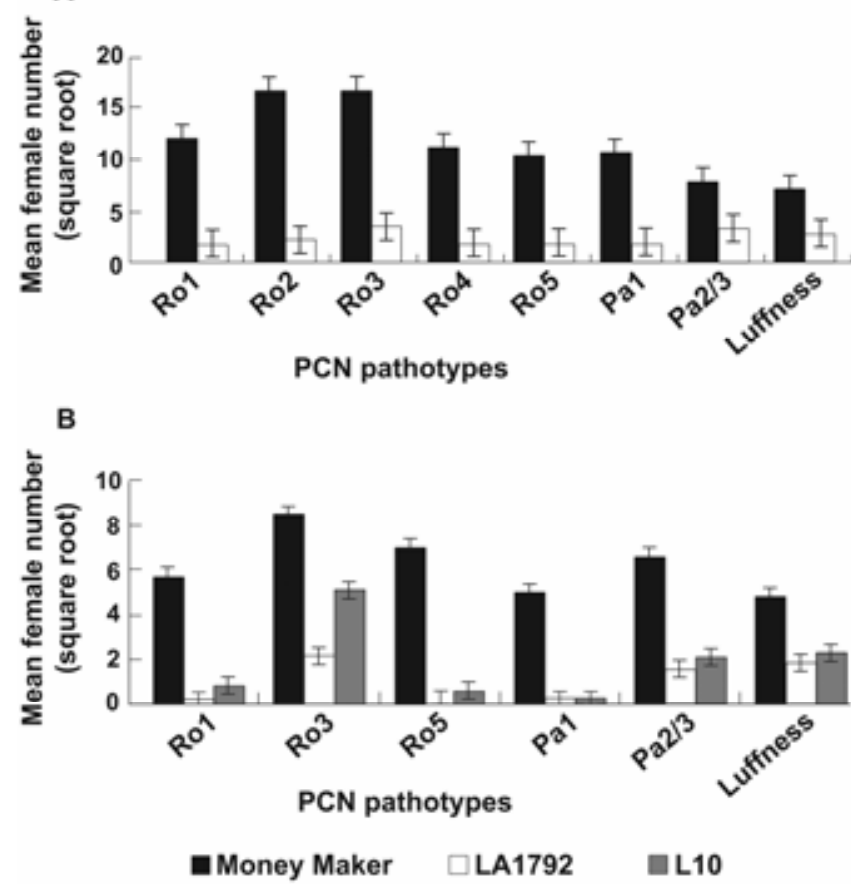

Fig. 1. A, Potato cyst nematode (PCN) tests showing the mean number of females (square root transformation) present on roots of susceptible tomato cv. Money Maker and resistant tomato line LA1792. B, PCN tests showing the mean number of females (square root transformation) present on roots of susceptible tomato cv. Money Maker, resistant tomato line LA1792, and transgenic L10. duced resistant line L10 (possessing a single copy of the Hero $A$ gene in a PCN-susceptible Money Maker background), has been performed. The potential applications and limitations of this broad-spectrum nematode resistance gene in plants with a view to producing PCN-resistant cultivars are discussed.

\section{RESULTS}

Evaluation of the pathotype specificity of the Hero gene.

Previously, a conventionally produced tomato line, LA1792, with the introgressed Hero gene family was shown to confer resistance to all pathotypes of a PCN, G. rostochiensis Ro1-5 (Ganal et al. 1995). Additionally, a preliminary characterization of the first selfed generation of transgenic tomato lines containing only the Hero A gene was shown to confer a high level $(>80 \%)$ of resistance to various pathotypes of $G$. rostochiensis (Ro1, Ro3 and, Ro5) and a degree of resistance to $G$. pallida $\mathrm{Pa} 2 / 3$ (Ernst et al. 2002). A further detailed analysis of the tomato line LA1792 has confirmed that the Hero gene behaves as a truly wide-spectrum major PCN resistance gene and confers a high level (>80\%) of resistance to all European pathotypes of $G$. rostochiensis (Ro1-5) and G. pallida (Pa1 and $\mathrm{Pa} 2 / 3$ ), as well as a particularly virulent population of $G$. pallida (Luffness) (Fig. 1A). Analysis of variance showed a significantly lower cyst counts on line LA1792 than on Money Maker $(P<0.001)$, irrespective of the PCN population used. In relative terms, the number of cysts on line LA1792 compared with Money Maker ranged from 1.8 to $4.5 \%$ with the $G$. rostochiensis populations; whereas, with G. pallida, the range was 3.3 to $19.0 \%$.

Additionally, a comprehensive PCN test on the fifth selfed generation of the transgenic tomato line L10, containing a single copy of the Hero A gene in homozygous condition, was performed along with the breeding line LA1792 and Money Maker as controls. To confirm the importance of the Hero $A$ gene in a PCN resistance breeding program, all important European pathotypes of $G$. rostochiensis (Ro1, Ro3, and Ro5) and

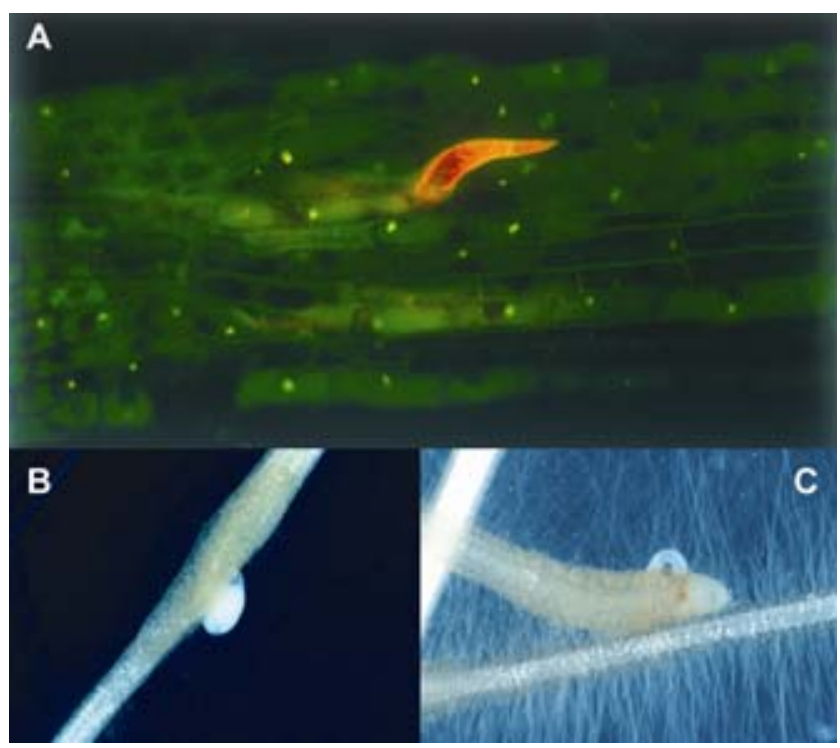

Fig. 2. A, Invasion of a juvenile into tomato root under in vitro conditions observed using a fluorescence confocal microscope (excitation maximum $=551 \mathrm{~nm}$, emission maximum $=567 \mathrm{~nm}$ ). Juveniles were stained with $\mathrm{PKH} 26$, the red fluorescent cell linker that binds to aliphatic molecules (e.g., lipids) in the cell membrane, allowing the dye to be incorporated into the whole surface of the nematode. B, A developing adult female on the susceptible cv. Money Maker roots. C, A developing adult male on the susceptible cv. Money Maker root. The two bottom pictures were taken under a dissecting microscope. 
G. pallida ( $\mathrm{Pa} 1, \mathrm{~Pa} 2 / 3$, and Luffness) were used. The transgenic L10 line with the Hero A gene has a comparable level of resistance to all pathotypes of both PCN species to that of the line LA1792 containing the Hero gene family (Fig. 1B). Significantly greater numbers of cysts were observed on Money Maker than on the LA1792 or L10 lines for all populations of PCN $(P<0.001)$. With the exception of the $G$. rostochiensis pathotype Ro3, the percentage of cysts observed on the LA1792 and L10 lines were not significantly different. This data also shows that the Hero $A$ gene remained stable and functional after five sexual generations in the tomato transgenic line.

\section{Invasion and development of juveniles in susceptible and resistant tomato roots.}

To characterize the development of PCN infection in tomato roots, an in vitro plant culture and nematode infection system was developed which allowed us to follow nematode developmental stages under the light microscope and to select relevant $\mathrm{PCN}$-infected root samples for further histological investigations. Invasion of a juvenile into tomato root under in vitro conditions is shown in Figure 2A. Juveniles were stained with $\mathrm{PKH} 26$, a red fluorescent cell linker that binds to aliphatic molecules (e.g., lipids) in the cell membrane, allowing the dye to be incorporated into the whole surface of the nematodes. The invasion of tomato roots by juveniles was observed using a fluorescence confocal microscope. The viability and invasion ability of juveniles were not affected by the PKH26 staining

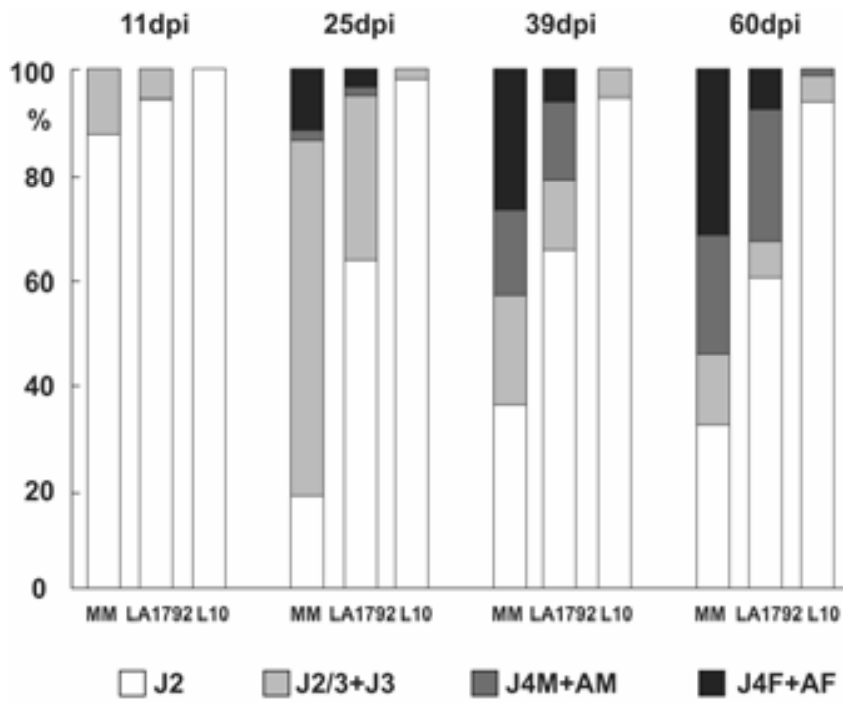

Fig. 3. Cumulative percentage of different developmental stages of juveniles developing on susceptible cv. Money Maker (MM), resistant line LA1792, and resistant transgenic line L10; dpi = days post inoculation; J2, $\mathrm{J} 2 / 3$, $\mathrm{J} 3$, and $\mathrm{J} 4=$ second, molting to third, third, and fourth juvenile stages, respectively; $\mathrm{AM}=$ adult male; and $\mathrm{AF}=$ adult female. process and stained juveniles could be visualized for at least the next 4 days. Developing adult females and males were observed on the susceptible cv. Money Maker roots under a dissecting microscope (Fig. 2B and C).

The most common pathotype of $G$. rostochiensis Rol was chosen to further investigate whether nematode development under aseptic in vitro conditions was different in the three tested tomato lines, Money Maker, LA1792, and L10. In vivo screening of infected plants indicated that total infection rates at 25 days postinoculation (dpi) (counted as a ratio between total juveniles used in inoculum and recovered inside plant roots) varied between 10 and $20 \%$ in all three tomato lines. These data indicate that the juveniles invaded roots of the susceptible and two resistant tomato lines to a similar extent. The percentage of different developmental stages of juveniles in the total population of juveniles entering the roots also was determined (Fig. 3). Juveniles molting to the J3 stage first were observed in susceptible Money Maker and resistant LA1792 lines 11 days after inoculation (12.4 and $5.7 \%$ of $\mathrm{J} 3$, respectively), whereas they were observed only 2 weeks later in the transgenic resistant L10 line $(1.8 \%$ of $\mathrm{J} 3$ at $25 \mathrm{dpi})$. At that time, on roots of susceptible Money Maker and resistant line LA1792, adult females already were present (11.7 and $3.2 \%$ of all juveniles, respectively). At the end of the experiment, 8 weeks after inoculation, in vitro PCN tests were comparable with pot experiments (data not shown). On average, in the roots of susceptible Money Maker, $30.8 \%$ of juveniles developed into adult females (Fig. 2B), 22.8\% developed into adult males (Fig. 2C), and $46.4 \%$ of juveniles remained in the $\mathrm{J} 2$ or J3 stage (Fig. 3). On roots of the resistant line LA1792 (with the Hero multigene family), the percentage of fully developed females was significantly lower $(7.5 \%)$, whereas the percentage of adult males was comparable $(25 \%)$. On the roots of transgenic line L10 (with the Hero A gene in the Money Maker background), almost all of the infesting juveniles remained in $\mathrm{J} 2$ or $\mathrm{J} 3$ stages and only $0.9 \%$ of juveniles developed into males. No female development was observed in these roots. Therefore, a higher percentage of juveniles were able to develop into adult stages on Money Maker than on LA1792 and L10 roots.

\section{Susceptible and resistant responses at the cellular level.}

Development of a functional syncytium is crucial for the successful completion of the life cycle of endoparasitic nematodes. To get insight into the nature of the Hero gene-mediated resistance in tomato plants, root colonization by pathotype Ro1 of G. rostochiensis of susceptible Money Maker was compared with that of resistant lines LA1792 (with the Hero multigene family) and L10 (with the Hero A gene) at the cellular level using light and electron microscopy.

\section{Syncytium development in susceptible Money Maker.}

Infective second-stage juveniles (J2) invaded roots and selected initial syncytial cells (ISC), usually among cortical cells

Fig. 4. Cross sections of roots of A-D, susceptible cv. Money Maker, E-F, resistant line LA1792, and G-H, resistant transgenic line L10 infested with Ro1 pathotype of Globodera rostochiensis; $\mathbf{B}$ and $\mathbf{F}, 2$ days after root invasion; $\mathbf{A}, \mathbf{C}, \mathbf{D}, \mathbf{E}, \mathbf{G}$, and $\mathbf{H}, 4$ days after root invasion; light micrographs for $\mathbf{A}$ and $\mathbf{E}$, bars $=20 \mu \mathrm{m}$; transmission electron micrographs for $\mathbf{B}, \mathbf{C}, \mathbf{D}, \mathbf{F}$, and $\mathbf{H}$, bars $2 \mu \mathrm{m}$, and $\mathbf{G}$, bar $1=\mu \mathrm{m}$. A, Syncytium composed of cells derived from cortex ("cortex bridge", CB) and procambial and pericyclic cells (asterisks) located next to the xylem vessels (X). Arrows point to cell wall openings. Section taken just above nematode's head. B, Part of syncytium formed by former procambial cells abutting xylem vessels (X). Arrows point to cell wall openings. C, Enlarged nuclei $(\mathrm{Nu})$ with nucleolus $(\mathrm{No})$ and irregularly shaped plastids $(\mathrm{Pl})$ in syncytial elements. D, Part of syncytial cortex bridge $(\mathrm{CB})$ with initial syncytial cell (ISC) with associated juvenile nematode (N). E, Syncytium composed of cells derived from cortex (CB) and procambial and pericyclic cells (asterisks) surrounded by necrosis (Ne). Arrows point to cell wall openings. Section taken just above nematode's head. F, Syncytial element (S) derived from pericycle surrounded by necrotized cells (Ne). Also, some procambial cells distant from syncytium had necrotized. G, Ultrastructure of syncytium (S) surrounded by necrotic cells $(\mathrm{Ne})$. A layer of new electron translucent cell wall material (arrows) is deposited. H, Degenerated syncytium (S) with electron translucent nuclei $(\mathrm{Nu}) . \mathrm{CW}=$ cell wall, $\mathrm{ER}=$ endoplasmic reticulum, $\mathrm{FP}=$ feeding plug, $\mathrm{FT}=\mathrm{feeding}$ tube, $\mathrm{M}=$ mitochondrion, $\mathrm{V}=\mathrm{vacuole}$. 


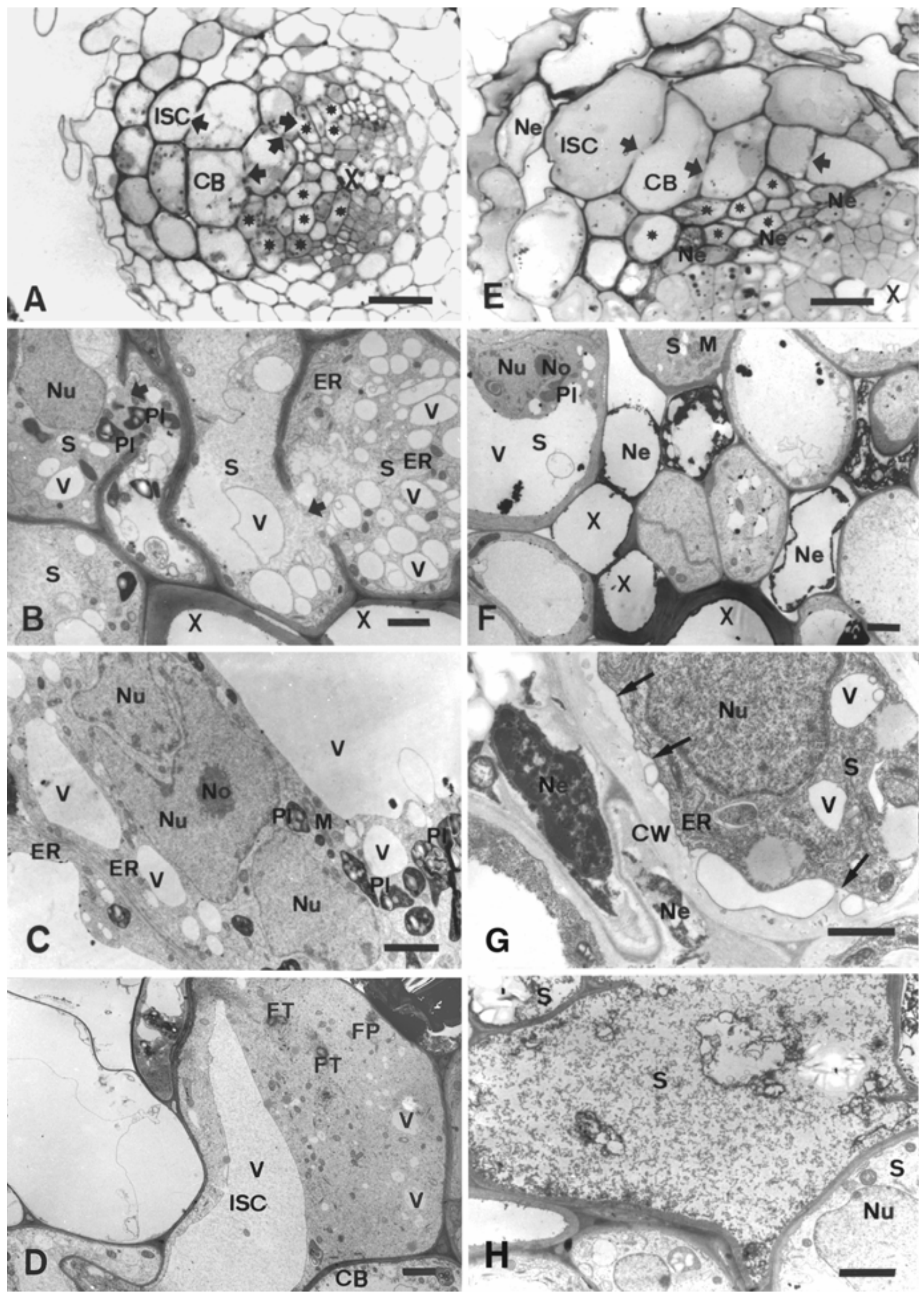


(Fig. 4A). Sometimes they entered a vascular cylinder and induced ISC in procambial cells. The ISC and some neighboring cells became enlarged and interconnected by local cell wall dissolutions (Fig. 4A and B). The widest cell wall openings were present in the area next to the nematode's head. In the case where the ISC were selected in cortex, a large part of syncytial volume was created by enlarged cortical and endodermal cells forming a so-called "cortex bridge" (Sembdner 1963) (Fig. 4A). In the vascular cylinder, the developing syncytium primarily incorporated procambial cells abutting xylem vessels in order to get direct contact with xylem vessels (Fig. 4A and B). No necrosis was observed around the syncytium, except in cells within the migration path of juveniles. Two days after root invasion, the syncytium was composed of approximately 50 to 100 cells. The amount of cytoplasm proliferated, especially in procambial and pericyclic cells that were incorporated as syncytial elements (Fig. 4B and C). Concomitantly, the central vacuoles gradually disappeared and new, small vacuoles appeared. In the 4-day-old syncytium, the mitochondria were not changed structurally or morphologically. In contrast, plastids began to acquire irregular shapes and they usually contained several starch grains (Fig. 4C). The system of endoplasmic reticulum was well developed and rough reticulum predominated. Syncytial nuclei already were enlarged in 2-day-old syncytia (Fig. 4B) and gradually became amoeboid or even lobbed shaped in 4-day-old syncytia (Fig. 4C). Observation of the feeding plug and numerous feeding tubes formed in each food withdrawal cycle indicated that nematodes were actively feeding on syncytia (Fig. 4D). Interestingly, a few underdeveloped and degenerated syncytia also were observed in the susceptible Money Maker roots, indicating that even the susceptible Money Maker roots may show a basal level of resistance to PCNs.

\section{Syncytium development}

in resistant breeding line LA1792 and transgenic line L10.

No differences were observed in nematode behavior in the resistant lines LA1792 and L10 during root penetration, invasion, and migration compared with the susceptible interaction. Furthermore, initial stages of syncytium development in roots of both resistant lines were similar to those in susceptible Money Maker. Infective $\mathbf{J} 2$ juveniles selected with similar frequency ISC in the cortex or in pericycle and procambium (Fig. $4 \mathrm{E})$. In contrast to susceptible interaction, necrotization was

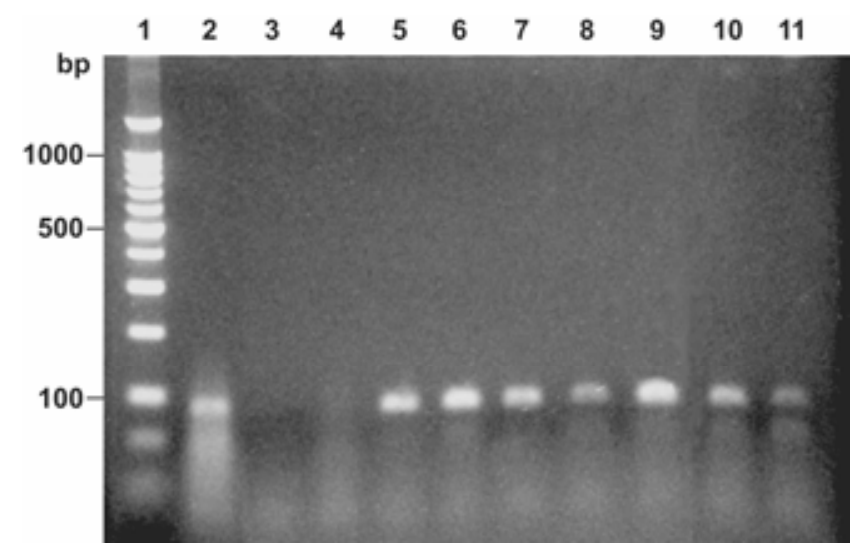

Fig. 5. Reverse-transcriptase polymerase chain reaction analysis showing expression of the Hero $A$ in different tissues of the transgenic tomato line $\mathrm{L} 10$ and roots of three independent transgenic potato lines. Lane $1=100$-bp marker, lane $2=$ cosmid A3246 harboring the Hero $A$ gene, lane $3=$ Desiree roots, lane $4=$ Money Maker roots, lane $5=\mathrm{L} 10$ roots, lane $6=\mathrm{L} 10$ stems, lane $7=$ L10 leaves, lane $8=$ L10 flower buds, lane $9=$ Desiree transgenic line $($ DesT24), lane $10=$ DesT11, and lane $11=$ DesT5 not restricted to the nematode migration path, but commonly was observed in procambial cells next to the xylem vessels or syncytia (Fig. 4E to G). Furthermore, 4 days after invasion, the ISC and cells incorporated into syncytium became enlarged and interconnected by local cell wall dissolutions (Fig. 4E). The cytoplasm content increased in syncytial elements during 2 days after root invasion, but they still contained central vacuoles with a relatively thin layer of the cytoplasm (Fig. 4F). Plastids and mitochondria were not changed morphologically and only some plastids contained starch grains. The system of endoplasmic reticulum was rather weakly developed compared with syncytia in roots of Money Maker (data not shown). The syncytial nuclei became slightly enlarged and only weakly amoeboid during early stages of syncytium development (Fig. $4 \mathrm{~F}$ and $\mathrm{G})$. Four days after root invasion, although the syncytium was well established, it was surrounded by a layer of necrotized cells also separating it from conductive tissues because of the rapid degeneration of surrounding cells (Fig.
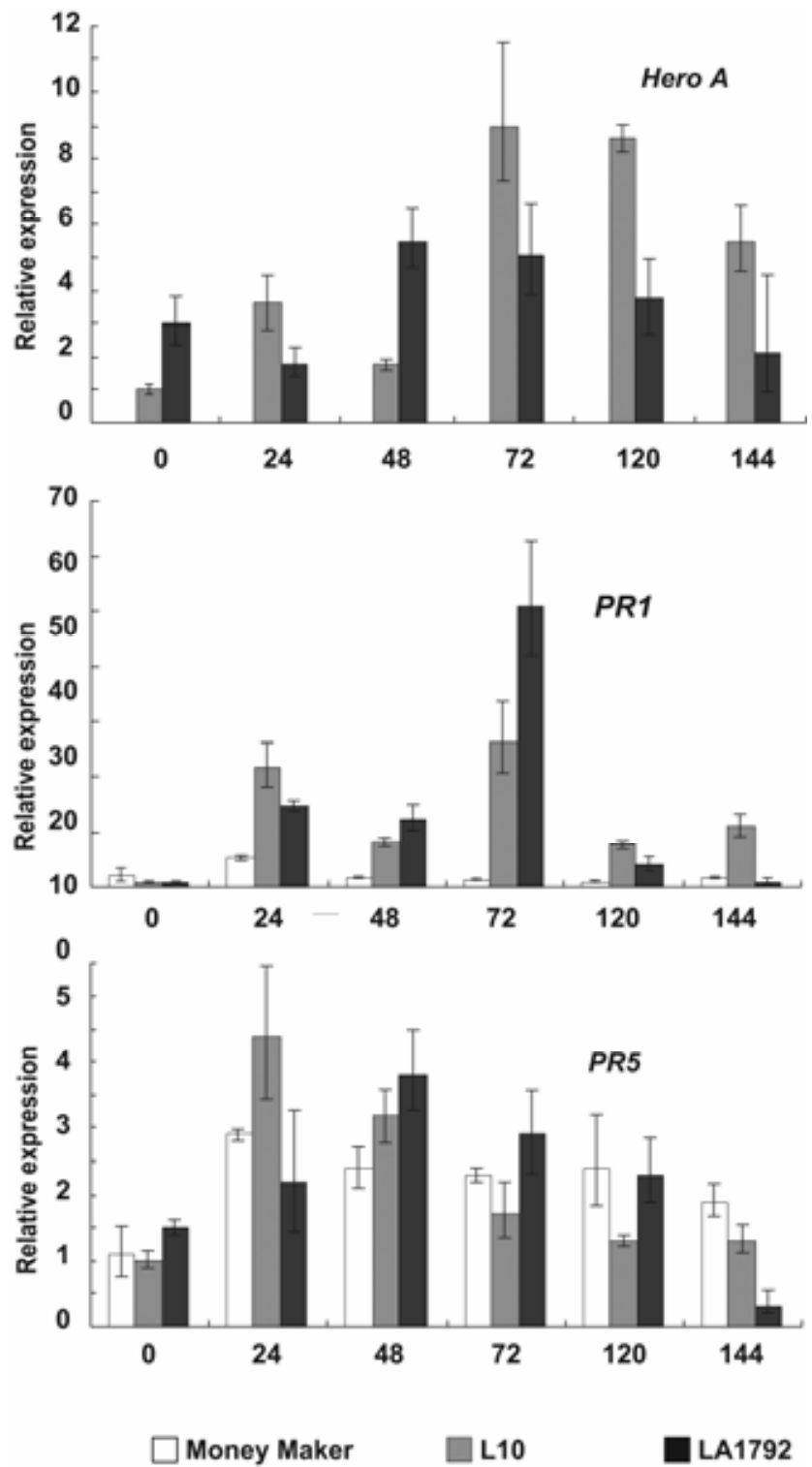

Fig. 6. Expression profiles of Hero A, PRI (P4) and PR5 (osmotin precursor, NP24) genes in roots of susceptible cv. Money Maker; resistant lines L10, containing Hero A gene; and LA1792, containing the Hero multigene family, uninfected (0) and 24, 48, 72, 120, and $144 \mathrm{~h}$ post inoculation with pathotype Ro1 of G. rostochiensis. Error bars represent confidence intervals calculated using three technical replicates for each sample within the reverse-transcriptase polymerase chain reaction assay. 
4G). Most of syncytia induced in the cortex as well as in the vascular cylinder also showed pronounced features of malfunction. At the ultrastructural level, the syncytial cytoplasm revealed two different stages of degeneration. At first, it became translucent and vacuolated. In line LA1792, the cytoplasm almost disappeared, leaving clearly delineated endoplasmic reticulum, vacuoles, mitochondria, and plastids; whereas, in line L10 in most syncytia, the cytoplasm seemed to be plasmolyzed and a layer of electron-translucent cell wall material was deposited in an irregular pattern (Fig. 4G). In addition to the remnants of the central vacuole, many small vacuoles were formed while cytoplasm became granular and osmiophilic. At the more advanced stage of necrotization, cytoplasm, nuclei, endoplasmic reticulum, plastids, and mitochondria disappeared and become unrecognizable (Fig. 4H). Such syncytia apparently were not capable of supporting developing juveniles. Nonetheless, $6.2 \%$ of all juveniles recovered inside L10 roots and $38.8 \%$ in LA1792 were able to develop to the J3 or older stages, indicating that initial defense responses may be overcome (Fig. 3). However, only $0.9 \%$ of juveniles were able to reach adult stage in roots of $\mathrm{L10}$, and all of them developed into males; no adult females were found. In contrast, in LA1792, 7.5\% of juveniles developed into adult females. This clearly demonstrates that Hero A gene-mediated resistance to PCNs in the transgenic L10 line is highly effective, at least under in vitro conditions.

\section{Expression profiles of the Hero $A, P R 1$, and $P R 5$ genes during PCN infection of tomato roots.}

To improve our understanding of the Hero gene-mediated resistance in tomato, the expression profiles of the Hero A gene and another two genes encoding pathogenesis-related (PR) proteins at various stages of PCN infection in both conventionally and transgenically produced resistant tomato lines were compared with that of susceptible Money Maker. Initial reverse-transcriptase polymerase chain reaction (RT-PCR) showed that Hero $A$ is expressed in all plant tissues, including roots, stems, leaves, and flower buds, from transgenic line L10 (Fig. 5) and breeding line LA1792 (data not shown). However, real-time quantitative RT-PCR analysis revealed the Hero $A$ gene being upregulated in roots during PCN infection of both resistant tomato lines LA1792 and L10 (Fig. 6). $\beta$-Tubulin was used as an endogenous control and the expression levels of all the genes investigated here were normalized against it. The expression level of each gene in the roots of uninoculated line L10 was assigned the basal value of 1.0 and the expression levels of the same gene in all the lines and at all time points were compared with it.

Taking into account that the entire root system of the infected plants was used for RNA extractions, and that synchronized nematode infection is very hard to achieve, the overall expression profiles of Hero $A$ in transgenic L10 line and conventional LA1792 line look similar. However, the Hero A gene upregula- tion was more pronounced in the transgenic L10 line starting from $24 \mathrm{~h}$ postinoculation (hpi), peaking at 72 to $120 \mathrm{hpi}$, and then gradually decreased up to 144 hpi (Fig. 6). In the conventional LA1792 line, the basal level of Hero A expression was approximately three times higher than in L10, but the peak level at 48 to 72 hpi was just over half of that in L10. Interestingly, the peak of the Hero A gene expression at 48 to 72 hpi in resistant tomato lines preceded the death of the syncytium at 4 days. These results suggest that the Hero A gene plays a role in inducing effective plant responses leading to the resistant phenotype.

A number of resistance genes, including nematode resistance genes, are known to trigger a well-defined set of defense related genes, including PR proteins (Gheysen and Fenoll 2002; Glazebrook 2001; Williamson and Gleason 2003). PR proteins have been shown to be good markers of the resistance response, because they are more strongly expressed during incompatible interactions than during compatible interactions. To investigate the role of the Hero $A$ gene in the regulation of the HR and possibly of defense responses, the expression profiles of the two PR protein genes, PRI (P4) and PR5 (osmotin precursor 24), representing salicylic acid (SA)-induced and uninduced classes of PR proteins (Cornelissen et al. 1986; Hugot et al. 2004; Kazan et al. 1998; Martinez de Ilarduya et al. 2003; Van Kan et al. 1995) were examined by quantitative real-time RT-PCR. After infection, the amount of PR5 transcripts increased slightly to a similar extent in all lines. In contrast, the expression of PR1 was dramatically increased in resistant lines only (Fig. 6). In the L10 line, the PRI expression level peaked at $24 \mathrm{hpi}$ and again at $72 \mathrm{hpi}$ after a drop in expression at $48 \mathrm{hpi}$. In the LA1792 line, the PRl expression level rose more slowly and peaked at $72 \mathrm{hpi}$, but again, as with Hero $A$, the overall expression profile of $P R l$ in both resistant lines was similar (Fig. 6). The upregulation of PR5 also was delayed slightly in line LA1792 in comparison with line L10, peaking at 48 and 24 hpi, respectively (Fig. 6).

Table 2. Relative levels of the tomato Hero $A$ gene expression in transgenic potato lines compared with transgenic tomato line L10

\begin{tabular}{lc}
\hline Tomato and potato lines $^{\mathbf{a}}$ & Relative levels of Hero $\boldsymbol{A}$ expression \\
\hline L10 & $1(0.90-1.11)$ \\
D1 & $0.13(0.12-0.14)$ \\
D5 & $0.49(0.46-0.53)$ \\
D6 & $0.60(0.50-0.71)$ \\
D7 & $0.06(0.05-0.07)$ \\
D8 & $0.14(0.12-0.17)$ \\
D11 & $1.25(1.05-1.48)$ \\
D14 & $18.13(16.80-19.56)$ \\
D20 & $15.56(15.03-16.45)$ \\
D21 & $0.06(0.05-0.08)$ \\
D24 & $3.01(2.69-3.36)$ \\
\hline
\end{tabular}

${ }^{a}$ Confidence intervals calculated using three technical replicates for each sample within the reverse-transcriptase polymerase chain reaction assay are given in parentheses.

Table 1. Sequences of oligonucleotide primers used in expression analysis and amplicon sizes

\begin{tabular}{|c|c|c|}
\hline Gene name, accession no. & Amplicon size (bp) & RT-PCR forward and reverse primers ${ }^{a}$ \\
\hline HeroA, (gi:23095860) & 89 & $\begin{array}{l}\text { 5'-GCATTGCAGATGGCTTGTG-3' } \\
\text { 5'-AGGACGTTGACATAACCCAACA-3' }\end{array}$ \\
\hline PR1 (P4), (gi:170487) & 81 & $\begin{array}{l}\text { 5'-GGTCGGGCTCGTTGCA-3' } \\
\text { 5'-AGGACGTTCTCCAACCCAGTT-3' }\end{array}$ \\
\hline Osmotin precursor (NP24), (gi:3747059) & 65 & $\begin{array}{l}\text { 5'-AGGTACGCAACAACTGTCCATACA-3' } \\
\text { 5'-ACGTCGACCACCGCCTATC-3' }\end{array}$ \\
\hline$\beta$-Tubulin, (gi:9455387) & 70 & $\begin{array}{l}\text { 5'-AACTTCGTGTTTGGCCAGTCA-3' } \\
\text { 5'-GCTCCGCTCCCTCAGTATAGTG-3' }\end{array}$ \\
\hline Actin, (gi: 47104110; gi: 21543) & 75 & $\begin{array}{l}\text { 5'-CCCCTTGTCTGTGACAATGGA-3' } \\
\text { 5'-AAATACAGCTCGTGGAGCATCA-3' }\end{array}$ \\
\hline
\end{tabular}

${ }^{\text {a }}$ RT-PCR = reverse-transcriptase polymerase chain reaction. 
The Hero $A$ gene does not confer resistance to $\mathrm{PCN}$ in transgenic potato.

In an attempt to transfer the Hero gene-mediated broadspectrum PCN resistance into potato, a total of 25 transgenic potato lines containing the Hero $A$ gene were generated and tested for PCN resistance with both $G$. rostochiensis Ro 1 and G. pallida $\mathrm{Pa} 2 / 3$. However, extensive PCN tests of these lines in glasshouse conditions did not show any significant levels of resistance to either of these PCN species (data not shown). In comparison, 18 of 20 transgenic tomato lines containing the Hero $A$ gene showed a significant level of resistance to PCN (Ernst et al. 2002). To confirm that the potato transgenic lines contained an intact tomato Hero $A$ gene, a number of primer combinations were designed, covering the entire region of the Hero A gene. PCR performed using transgenic potato genomic DNA samples as template showed that the majority of these transgenic potato lines contained a "complete" copy of the Hero A gene. Additionally, RT-PCR analysis on cDNA samples from transgenic potato lines were performed using the Hero $A$ gene-specific primers (Table 1) to confirm that these lines were expressing the tomato Hero $A$ gene, and data from three of these lines are included in Figure 5. Furthermore, real-time RT-PCR was performed to compare levels of the tomato Hero A gene expression in 10 transgenic potato lines to that in transgenic tomato line L10, assigned the basal value of 1.0. Primers were designed to anneal to both tomato and potato actin gene (Table 1) that was used as an endogenous control. Although transgenic potato lines showed some variation in the relative levels of Hero $A$ gene expression (from 0.06- to 18.13-fold the level in L10), most of these lines were transcribing the tomato Hero A gene at levels similar to or even higher than those in the tomato transgenic line L10 (Table 2). Thus, the inability of transgenic potato plants to confer resistance to $\mathrm{PCN}$ is not due to the lack of expression of the tomato Hero A gene in them.

\section{DISCUSSION}

Comprehensive PCN tests carried out on the breeding line LA1792 with the complete set of the Hero genes and the transgenic line L10 containing a single copy of the Hero A gene revealed that they have not only a high level of resistance to all pathotypes of $G$. rostochiensis but also to all major pathotypes of G. pallida: Pa1, Pa2/3, and the highly virulent Luffness population. Such a broad-spectrum major PCN resistance gene has not been identified previously in Solanum spp., making the Hero A gene potentially very important for generating PCN resistant cultivars within Solanum spp. Additionally, the Hero gene-mediated resistance provides an ideal model system for investigating the mechanism of action of a broad-spectrum disease resistance gene.

The PCN in vitro infection data indicated that both susceptible Money Maker and the two resistant lines LA1792 and L10 were infected by a similar number of juveniles. This is in agreement with other reports on the root penetration rates of cyst nematodes being similar for resistant and susceptible cultivars (Acedo et al. 1984; Müller 1985; Phillips et al. 1982; Roberts and Stone 1983). In all tomato lines tested here, some juveniles were unable to develop beyond $\mathrm{J} 2$ and J3 stages. However, the percentage of juveniles beyond J2 and J3 stages varied greatly between susceptible and resistant genotypes and was dependent on the observation time points. In general, the number of $\mathrm{J} 4$ and adults was highest in susceptible Money Maker and lowest in both resistant lines carrying the Hero $A$ gene. Moreover, in the resistant transgenic line L10, only $7 \%$ of invaded juveniles developed beyond $\mathrm{J} 2$ (i.e., J3 and male stages). Additionally, development of juve- niles on roots of resistant transgenic line L10 was delayed compared with the susceptible Money Maker and LA1792 lines. Interestingly, the upregulation of the Hero A gene in the transgenic line L10 was more pronounced than in the "original" introgressed line LA1792, although the native promoter drives expression in both of these tomato lines. The reasons for the differences in the expression profile of the Hero $A$ gene in these two lines is unknown, but it could be due to the influence of the genomic sequences adjacent to the insertion site of the transgene or the differences in the genetic background between them (i.e., LA1792 has Alisa Craig and L10 has Money Maker genotype).

Histological analyses have revealed that syncytium induction and initial stages of its development in all three tomato genotypes (Money Maker, LA1792, and L10) were similar. However, there were some clear differences in the later stages of syncytium development with respect to timing and types of cells subjected to necrotization in the two resistant lines, LA1792 and L10, compared with the susceptible Money Maker. For example, in both resistant lines, procambial cells in direct contact with the xylem vessels, but not included into growing syncytium, were necrotized, thereby preventing the growing syncytium from getting in contact with the xylem tracheary elements. The crucial role of these cells in the development of a functional syncytium during susceptibility and resistance responses in white mustard to infection with $H$. schachtii have been reported previously (Golinowski and Magnusson 1991). In susceptible plants, highly metabolically active syncytia are developed, and this demands the establishment of effective transcriptional and ribosome synthesis machineries situated in syncytial nuclei and nucleoli (Bleve-Zacheo et al. 1990; Grymaszewska and Golinowski 1998; Melillo et al. 1990). As a consequence, in the susceptible Money Maker, the enlargement of nuclei began early, upon infection, and the outlines of the nuclei became amoeboid. Nuclei contained reduced amounts of heterochromatin and their nucleoplasm was condensed, indicating their high activity. In the resistant LA1792, syncytial nuclei also enlarged but their outlines were only slightly amoeboid. Moreover, in the resistant transgenic line L10, no nuclear hypertrophy in syncytia nuclei took place prior to syncytium degradation. It seems that degradation of syncytial cytoplasm was followed by degradation of syncytial nuclei. A similar observation during resistance responses in soybean has been described (Kim et al. 1987).

This study has revealed that the level and the nature of resistance in both LA1792 and L10 are similar, in spite of the fact that the L10 line contains only the Hero A gene, whereas LA1792 contains the complete 13 copies of the Hero gene family. Furthermore, the Hero A gene-mediated resistance response is of a delayed HR type, in which juveniles are able to invade and induce a syncytium even in the resistant roots. The resistance responses appear to be triggered after or during the development of syncytium within 2 to 4 days postinvasion, leading to degradation of syncytium and, therefore, preventing developing juveniles from obtaining nutrients. This leads to the starvation of most of juveniles in $\mathrm{J} 2$ stage and to surviving nematodes developing mostly into males. The average sex ratio (male/female) was approximately 0.74 in susceptible Money Maker and 3.32 in resistant line LA1792. Interestingly, no female adults were found in the transgenic line L10, at least under in vitro conditions. Thus, the ratio between males and females is strongly biased toward males, resulting in severe reduction in multiplication of the invading nematodes. This type of so called "male-based resistance" is commonly observed against cyst-forming nematodes (Acedo et al. 1984; Müller 1985; Phillips et al. 1982; 
Rice et al. 1985; Roberts and Stone 1983; Turner and Stone 1984). In contrast, the $M i$ gene-mediated resistance response is of the rapid HR type, in which the invading juveniles of root-knot nematodes (Meloidogyne incognita) are restricted to initiating giant cell development (Milligan et al. 1998). Recent studies on the $M i$ gene has revealed that both $\mathrm{N}$ terminus and LRR regions of the gene are responsible for the activation of a rapid HR-type reaction leading to localized cell death (Hwang and Williamson 2003; Hwang et al. 2000). Both Hero and Mi genes belong to the family of the NBSLRR class of resistance genes; therefore, it would be interesting to find out how these genes are able to activate two very different types of resistance responses in plants following interactions with nematodes.

Like the Hero A transcript, the Mi-1.2 transcript has been shown to accumulate in seeds, stems, leaves, flowers, and green fruit of uninfected resistant tomato lines but not susceptible tomato lines (Martinez de Ilarduya and Kaloshian 2001; Milligan et al. 1998). However, in contrast to Hero A transcripts, the levels of $M i-1.2$ transcripts do not change during root-knot nematode infection, which is consistent with a rapid HR-type response. The upregulation of the Hero $A$ gene expression during infection supports the hypothesis that resistance genes are expressed all the time in most of the tissues as surveillance proteins to detect products from pathogens directly or indirectly (Martin et al. 2003), and may change their expression profiles as a result of complex interactions between the products of the resistance gene and pathogens. Because the Hero A gene upregulation correlated with the timing of degradation of the syncytium, it is tempting to suggest that the upregulation of the Hero $A$ gene may be a prerequisite to effectively activating a cascade of signal transduction pathways leading to resistant responses and phenotype. To investigate the role of the Hero A gene in the regulation of the HR and defense responses, the expression profiles of $P R 1$ and $P R 5$ genes, representing SAinduced and uninduced classes of PR proteins, were included in these analyses (Cornelissen et al. 1986; Hugot et al. 2004; Kazan et al. 1998; Martinez de Ilarduya et al. 2003; Van Kan et al. 1995). Our results clearly demonstrate that the PRI gene expression after infection is much more elevated in lines containing the Hero gene. In contrast, the expression profile of $P R 5$, the SA-uninduced PR protein, was similar in all three lines. The early upregulation of a member of $P R I$ gene family in resistant lines during infection confirms the presence of active signaling to induce the plant defense responses leading to $\mathrm{HR}$ and arrested development of the invading nematode. Recently, it has been indicated that SA is an important component of the signaling that leads to nematode resistance and the associated HR in the Mi-1.2 genemediated resistance response (Branch et al. 2004).

Unfortunately, none of the transgenic potato plants expressing the tomato Hero A gene were able to confer resistance to PCN species. Similarly, it has been demonstrated that the tomato $M i$ gene does not confer resistance to root-knot nematodes in transgenic tobacco lines (Williamson 1998). These results have important implications in utilizing any major disease resistance genes for enhancing resistance across species by genetic transformation. It is not known why the Hero $A$ gene does not confer resistance to nematodes in potato, but it is likely that, in the potato genome, some genes either are missing or not expressed strongly enough or at the appropriate time to form the complex with the products of resistance $(R)$ and avirulence ( $a v r)$ genes that is required for the activation of the cascade of signal transduction pathways leading to resistance phenotype. Microarray-based technology together with functional genomic approaches might help to identify a wide range of host resistance-responsive genes that are involved in the Hero A gene-mediated resistance and may provide some clues as to why the tomato Hero $A$ gene is unable to confer resistance in transgenic potato plants.

\section{MATERIALS AND METHODS}

\section{Plant materials.}

Seeds of PCN-susceptible tomato (Lycopersicon esculentum L.) cv. Money Maker originated from Sutton Seed. Seeds of PCN-resistant tomato (L. esculentum L.) line LA1792, containing the Hero gene cluster, were provided by the Tomato Genetic Stock Center, University of California, Davis, U.S.A. The transgenic tomato line L10 previously was produced by Agrobacterium-mediated transformation and, based on the Southern blot and genetic data, contains a single copy of the Hero $A$ gene, and the expression of the gene is under the control of its own native promoter (Ernst et al. 2002). Seeds of transgenic PCN-resistant tomato line L10 were generated by selfing for five sexual generations, which led to the L10 line being homozygous for the introduced Hero A gene.

PCNs.

G. rostochiensis Woll. pathotypes Ro1, Ro2, Ro3, Ro4, and Ro5 and G. pallida pathotypes $\mathrm{Pa} 1$ and $\mathrm{Pa} 2 / 3$ were used for PCN resistance tests. In addition, a population of $G$. pallida Luffness (originally identified in the field in the East Lothian, Scotland, U.K.) showing very high virulence on some partially resistant potato genotypes derived from $S$. vernei also was included. All the nematode pathotypes were maintained at Scottish Crop Research Institute, Dundee, Scotland.

\section{PCN tests in the petri dishes.}

For in vitro development and microscopic examination, seeds of all three lines were surface-sterilized in $70 \%$ ethanol for 2 min followed by soaking in $10 \%$ solution of the commercially available detergent Clorox (a germicidal bleach solution containing $7.3 \%$ sodium hypochlorite; Oakland, CA, U.S.A.) for $20 \mathrm{~min}$. Seeds were washed extensively in sterile distilled water for $30 \mathrm{~min}$ and transferred onto petri dishes containing $0.8 \%$ water agar and left in darkness at $20^{\circ} \mathrm{C}$ for germination. Germinated seeds were aseptically transferred into $90-\mathrm{mm}$ petri dishes containing $0.2 \mathrm{KNOP}$ medium ( $\mathrm{Si}$ jmons et al. 1991) and were grown in sealed dishes for 14 days at $20^{\circ} \mathrm{C}$ under a $16-\mathrm{h}$ photoperiod and $110 \mu \mathrm{E} \mathrm{m} \mathrm{m}^{-2} \mathrm{~s}^{-1}$. For in vitro nematode development tests and microscopic analysis, the second-stage infective juveniles (J2) of the Ro1 pathotype of $G$. rostochiensis were hatched in potato root exudates. The freshly hatched juveniles were surface sterilized in a solution composed of $0.025 \% \mathrm{HgCl}_{2}$ and $1 \%$ streptomycin (Sigma, Poole, U.K.) for $3 \mathrm{~min}$ and then extensively washed in several changes of sterile distilled water (Kumar and Forrest 1990). The aerial parts of tomato plants were cut off just before inoculation with approximately 150 sterile $\mathrm{J} 2 \mathrm{~s}$. The dishes were sealed with parafilm and left in darkness at $20^{\circ} \mathrm{C}$. The developmental stages of juveniles that invaded tomato roots were assessed using an inverted dissecting microscope at 11, 25, 39, and 60 days after inoculation. The experiment was repeated twice and, in all, 20 Money Maker, 30 LA1792, and 18 L10 plants were examined. The mean values and standard deviations were calculated using Microsoft Excel.

For microscopic examinations, the inoculated roots were screened for the presence of $\mathrm{J} 2 \mathrm{~s}$ inside the roots each day after inoculation. Samples containing segments of the roots with juveniles were collected at 2 and 4 days after root invasion. Only samples with associated single juveniles were collected 
and processed. They were fixed, osmicated, dehydrated in ethanol and acetone, and embedded in epoxy resin (Fluka) as described by Golinowski and associates (1996). Semithin (2 $\mu \mathrm{m}$ thick) and ultrathin ( 70 to $80 \mathrm{~nm}$ thick) sections were cut with glass and diamond knives, respectively, using a Reichert Ultracut E (Leica, Bensheim, Germany) ultramicrotome. Semithin sections were stained with hot $0.5 \%$ Toluidine Blue for $30 \mathrm{~s}$. Ultrathin sections were collected on pyroxilinecoated 100-mesh nickel grids and stained for 4 min with a saturated $50 \%$ ethanol solution of uranyl acetate, followed by 6 min of staining with an aqueous solution of lead citrate. The sections were examined using Phillips CM10 or Joel JEM 1200AX transmission electron microscopes.

\section{PCN staining with fluorescent dye PKH26.}

The lipid probe PKH26 was obtained as the PKH26 red fluorescent Cell linker kit (lot no. 111K0988; Sigma). PKH26 is provided as a stock solution of $1 \mathrm{mM}$ in $100 \%$ ethanol. All PKH26 labeling experiments were performed using sterile distilled water for washing and dilution. Freshly hatched and surface-sterilized juveniles were incubated in an Eppendorf tube containing diluted PKH26 solution (1:1000) for $10 \mathrm{~min}$ at room temperature. Following incubation, labeled juveniles were washed and collected by centrifugation at low speed. The stained juveniles were transferred onto in vitrogrown tomato roots as described above and incubated in the dark for 12 to $24 \mathrm{~h}$. Only the invasion process of juveniles in the tomato roots was observed using a fluorescence confocal microscope (excitation maximum. $=551 \mathrm{~nm}$ and emission maximum $=567 \mathrm{~nm})$.

\section{PCN tests in the glasshouse.}

Testing for PCN resistance using different pathotypes of $G$. rostochiensis and G. pallida was carried out in the containment glasshouse as described by Ganal and associates (1995). The PCN-susceptible tomato Money Maker was used as a control in all PCN tests along with the two PCN-resistant lines, LA1792 (breeding line) and L10 lines (transgenic line). The resistance tests included five independent replications. Each plant was inoculated with 20 cysts. Examination of the roots for presence of adult females was carried out 8 weeks after inoculation. Plants were classified as resistant if plants harbored, on average, fewer than six cysts.

\section{RNA isolation and cDNA synthesis.}

Flower buds, stems, leaves, and entire root systems from PCN-infected and -uninfected tomato plants and root tissue of uninfected potato transgenic lines were collected separately, instantly frozen in liquid nitrogen, and stored at $-70^{\circ} \mathrm{C}$ prior to RNA extraction. Total RNA was extracted from frozen samples using the Qiagen RNeasy plant mini kit (Qiagen, Crawley, U.K.) following the protocol supplied by the manufacturer. Integrity and yield of the RNA was tested by agarose gel electrophoresis. Prior to cDNA synthesis, RNA samples were treated with RNase-free DNase (DNA Free kit; Ambion, Austin, TX, U.S.A.), following the manufacturer's protocol. RNA concentration was determined using a spectrophotometer (Beckman Instruments, Irvine, CA, U.S.A.). First-strand cDNA was synthesized from $20 \mu \mathrm{g}$ of total RNA by oligo dT priming using a first-strand cDNA synthesis kit (Amersham Pharmacia Biotech, Hertfordshire, U.K.), following the manufacturer's protocol. Resulting cDNA samples were checked for the presence of any remaining genomic DNA by using a specific pair of primers spanning an intron of the spliceosome U1snRNP gene (Ibrahim et al. 2001) and thus producing a bigger PCR product from genomic DNA than from cDNA.
RT-PCR and SYBR green real-time RT-PCR assays.

Primer pairs (Table 1) were designed for each sequence with the Primer Express software supplied with the ABI PRISM 7700 Sequence Detection System (Applied Biosystems, Foster City, CA, U.S.A.) and following the manufacturer's guidelines for primer design. Hero family members were aligned prior to designing Hero A-specific primers to identify a region in the $3^{\prime}$ untranslated region of the gene with highest diversity. The specificity of the Hero A primers were checked by PCR with cosmids individually containing each of the 13 members of the Hero gene family. Only cosmids containing the Hero A gene gave a PCR product of expected size (Fig. 5). RT-PCR was performed on cDNA samples from different tissues of the transgenic tomato line $\mathrm{L} 10$ and roots of three independent transgenic potato lines with relevant controls using the same Hero $A$ gene-specific primers (Table 1) under these conditions: $96^{\circ} \mathrm{C}$ for $2 \mathrm{~min}$; followed by 30 cycles of $15 \mathrm{~s}$ at $96^{\circ} \mathrm{C}, 30 \mathrm{~s}$ at $60^{\circ} \mathrm{C}$, and $90 \mathrm{~s}$ at $72^{\circ} \mathrm{C}$; and finally $72^{\circ} \mathrm{C}$ for $5 \mathrm{~min}$. The PCR products were visualized by ethidium-bromide staining on $2 \%$ agarose gel.

For SYBR green real-time RT-PCR assays, the amplification efficiency of all primer pairs (Table 1) was optimized with L10 genomic DNA as a template. Primer concentrations giving the lowest threshold cycle $(\mathrm{Ct})$ value were selected for further analysis. Direct sequencing of PCR products using real-time RT-PCR primer pairs revealed that only the target sequence was amplified. Detection of real-time PCR products was by binding of the fluorescent DNA dye SYBR green (SYBR green PCR master mix; Applied Biosystems) to PCR products. All assays were carried out in triplicate, and appropriate controls were included (no template control). Assays were repeated on independent occasions, with independently isolated RNA and subsequently synthesized cDNA samples. All reactions were heated to $50^{\circ} \mathrm{C}$ for $2 \mathrm{~min}$ and $95^{\circ} \mathrm{C}$ for 10 min, followed by 40 cycles of $95^{\circ} \mathrm{C}$ for $15 \mathrm{~s}$ and $60^{\circ} \mathrm{C}$ for 1 min. After PCR, all samples were electrophoresed on agarose gels to verify amplification, and compared with results from the 7700 Sequence Detection System. Amplification efficiency of all genes of interest and the endogenous controls ( $\beta$-tubulin and actin) were shown to be equivalent, allowing the use of the comparative $\mathrm{Ct}$ method $(\Delta \Delta \mathrm{Ct})$ for relative quantification of gene expression levels at different time points after inoculation in relation to their expression in uninoculated roots and direct comparison of gene expression between tomato and potato lines. Primers were designed to anneal to both the tomato and potato actin gene to allow direct comparison of gene expression between tomato and potato lines. An equal fluorescence yield during real-time RT-PCR per initial $\beta$-tubulin (actin) transcript was assumed. All calculations and statistical analyses were performed as described in the ABI PRISM 7700 Sequence Detection System User Bulletin \#2 (Applied Biosystems). Confidence intervals were calculated using three technical replicates for each sample within the RT-PCR assay.

\section{Production of transgenic potato lines containing the tomato Hero $A$ gene.}

Transgenic potato lines containing the tomato Hero $A$ gene were produced by an Agrobacterium-mediated transformation (Kumar 1994) of PCN-susceptible potato cv. Desiree using the same construct that was used previously to transform tomato lines (Ernst et al. 2002). This construct contains within $17 \mathrm{~kb}$ the complete Hero A gene, $8.5 \mathrm{~kb}$ of upstream and $2.3 \mathrm{~kb}$ of downstream sequence (accession no. AX 337979 from 9,986 to 23,641 bp and AJ457052.1), ligated to BamH1-digested binary cosmid vector TDNA04541 (Jones et al. 1992). Putative potato transgenic lines were characterized for the presence and expres- 
sion of the tomato Hero $A$ gene before testing for resistance to PCN using the following primer pairs: 5'-AGGATTGCCCAA GCTTTAC-3'/M13 reverse, 5'-CAACTCTCTATCACTAGTTC3'/M13 forward, 5'-TTGAACCTCCAGAATCTG-3'/5'-ATTC TCACCTTCCAATATTC-3', 5'-CGTATATATTTTTTCATCTG C-3'/5'-GAGTATTTCACTATGGTG-3', and 5'-ATATTGAAG GCTGGTTGG-3'/5'-TCATTATTTGCTTCAAACC-3'.

\section{ACKNOWLEDGMENTS}

We thank A. Holt, A. Paterson, M. Szelag, and M. Wasilewska-Gomulka for their excellent assistant with PCN tests, tissue culture, and microtome work; and P. Birch for his useful advice on the plant gene expression study. M. Sobczak is grateful to the Royal Society for a NATO postdoctoral fellowship award and to the British Council in Warsaw for a traveling grant during the prefellowship period. A. Avrova, A. Kumar, and M. S. Phillips acknowledge financial support from the Scottish Executive Environment Rural Affairs Department (SEERAD).

\section{LITERATURE CITED}

Acedo, J. R., Dropkin, V. H., and Luedders, V. D. 1984. Nematode population attrition and histopathology of Heterodera glycines-soybean associations. J. Nematol. 16:48-57.

Bleve-Zacheo, T., Bongiovanni, M., Melillo, M. T., and CastagnoneSereno, P. 1998. The pepper resistance genes $\mathrm{Mel}$ and $\mathrm{Me} 3$ induce differential penetration rates and temporal sequences of root cell ultrastructural changes upon nematode infection. Plant Sci. 133:79-90.

Bleve-Zacheo, T., Melillo, M. T., and Zacheo, G. 1990. Ultrastructural response of potato roots resistant to cyst nematode Globodera rostochiensis pathotype Ro1. Rev. Nematol. 13:29-36.

Branch, C., Hwang, C.-F., Navarre, D. A., and Williamson, V. M. 2004. Salicylic acid in part of the Mi-1-mediated defense response to rootknot nematode in tomato. Mol. Plant-Microbe Interact. 17:351-357.

Brodie, B. B., Evans, K., and Franco, J. 1998. Nematode parasites of potato. Pages 87-132 in: Plant Parasitic Nematodes in Temperate Agriculture. K. Evans, D. L. Trudgill, and J. M. Webster, eds. CAB International, Wallingford, U.K.

Cai, D., Kleine, M., Kifle, S., Harloff, H. J., Sandal, N. N., Marcker, K. A., Klein-Lankhorst, R. M., Salentijn, E. M., Lange, W., and Stiekema, W. J., Wyss, U., Grundler, F. M. W., and Jung. C. 1997. Positional cloning of a gene for nematode resistance in sugar beet. Science 275:832-834.

Cornelissen, B. J., Hooft van Huijsduijnen, R. A., and Bol, J. F. 1986. A tobacco mosaic virus-induced tobacco protein is homologous to the sweet-tasting protein thaumatin. Nature 321:531-532.

Ellis, P. R., and Maxon-Smith, J. W. 1971. Inheritance of resistance to potato cyst-eelworm (Heterodera rostochiensis Woll.) in the genus Lycopersicon. Euphytica 20:93-101.

Ernst, K., Kumar, A., Kriseleit, D., Kloos, D.-U., Phillips, M. S., and Ganal, M. W. 2002. The broad-spectrum potato cyst nematode resistance gene (Hero) from tomato is the only member of a large gene family of NBSLRR genes with an unusual amino acid repeat in the LRR region. Plant J. 31:127-136.

Ganal, M. W., Simon, R., Brommonschenkel, S., Arndt, M., Phillips, M. S., Tanksley, S. D., and Kumar, A. 1995. Genetic mapping of a wide spectrum nematode resistance gene (Hero) against Globodera rostochiensis in tomato. Mol. Plant-Microbe Interact. 8:886-891.

Gheysen, G., and Fenoll, C. 2002. Gene expression in nematode feeding sites. Annu. Rev. Phytopathol. 40:191-219.

Glazebrook, J. 2001. Genes controlling expression of defense responses in Arabidopsis- 2001 status. Curr. Opin. Plant Biol. 4:301-308.

Golinowski, W., Grundler, F. M. W., and Sobczak, M. 1996. Changes in the structure of Arabidopsis thaliana during female development of the plant-parasitic nematode Heterodera schachtii. Protoplasma 194:103116.

Golinowski, W., and Magnusson, C. 1991. Tissue response induced by Heterodera schachtii (Nematoda) in susceptible and resistant white mustard cultivars. Can. J. Bot. 69:53-62.

Grymaszewska, G., and Golinowski, W. 1998. Structure of syncytia induced by Heterodera schachtii Schmidt in roots of susceptible and resistant radish (Raphanus sativus L. var. oleiformis). Acta Soc. Bot. Pol. 67:207-216.

Holtmann, B., Kleine, M., and Grundler, F. M. W. 2000. Ultrastructure and anatomy of nematode-induced syncytia in roots of susceptible and resistant sugar beet. Protoplasma 211:39-50.

Hugot, K., Rivière, M.-P., Moreilhon, C., Dayem, M. A., Cozzitorto, J., Arbiol, G., Barbry, P., Weiss, C., and Galiana, E. 2004. Coordinated
Regulation of Genes for Secretion in Tobacco at Late Developmental Stages: Association with Resistance against Oomycetes. Plant Physiol. 134:858-870

Hwang, C. F., Bhakta, A. V., Truesdell, G. M., Pudlo, W. M., and Williamson, V. M. 2000. Evidence for a role of the N terminus and leucine-rich repeat region of the $M i$ gene product in regulation of localized cell death. Plant Cell 12:1319-1329.

Hwang, C. F., and Williamson, V. M. 2003. Leucine-rich repeat-mediated intermolecular interactions in nematode reorganization and cell death signaling by the tomato resistance protein $\mathrm{Mi}$. Plant J. 34:585-593.

Ibrahim, A. F. M., Watters, J. A., and Brown, J. W. S. 2001. Differential expression of potato U1A spliceosomal protein genes: A rapid method for expression profiling of multigene families. Plant Mol. Biol. 45:449-460.

Jones, J. D., Shlumukov, L., Carland, F., English, J., Scofield, S. R., Bishop, G. J., and Harrison, K. 1992. Effective vectors for transformation, expression of heterologous genes, and assaying transposon excision in transgenic plants. Transgenic Res. 6:285-297.

Jones, M. G. K., and Northcote, D. H. 1972. Nematode-induced syncytium-a multinucleate transfer cell. J. Cell Sci. 10:789-809.

Kazan, K., Murray, F. R., Goulter, K. C., Llewellyn, D. J., and Manners, J. M. 1998. Induction of cell death in transgenic plants expressing a fungal glucose oxidase. Mol. Plant-Microbe Interact. 11:555-562.

Kim, Y. H., Riggs, R. D., and Kim, K. S. 1987. Structural changes associated with resistance of soybean to Heterodera glycines. J. Nematol. 19:177187.

Kumar, A. 1994. Agrobacterium-mediated transformation of potato genotypes. Pages 121-128 in: Agrobacterium Protocols, Methods in Molecular Biology. K. V. Gartland and M. R. Davey, eds. Humana Press, Totowa, NJ, U.S.A

Kumar, A., and Forrest, J. M. S. 1990. Reproduction of Globodera rostochiensis on transformed roots of Solanum tuberosum cv. Desiree. J. Nematol. 22:395-398.

Martin, G. B., Bogdanove, A. J., and Sessa, G. 2003. Understanding the functions of plant disease resistance proteins. Annu. Rev. Plant Biol. 54:23-61.

Martinez de Ilarduya, O., and Kaloshian, I. 2001 Mi-1.2 transcripts accumulate ubiquitously in root-knot nematode resistant Lycopersicon esculentum. J. Nematol. 33:116-120.

Martinez de Ilarduya, O., Xie, Q., and Kaloshian, I. 2003. Aphid-induced defense responses in Mi-1-mediated compatible and incompatible tomato interactions. Mol. Plant-Microbe Interact. 16:699-708.

Melillo, M. T., Bleve-Zacheo, T., and Zacheo, G. 1990. Ultrastructural response of potato roots susceptible to cyst nematode Globodera pallida pathotype Pa3. Rev. Nématol. 13:17-28.

Milligan, S. B., Bodeau, J., Yaghoobi, J., Kaloshian, I., Zabel, P., and Williamson, V. M. 1998. The root knot nematode resistance gene $M i$ from tomato is a member of the leucine zipper, nucleotide binding, leucine-rich repeat family of plant genes. Plant Cell 10:1307-1319.

Müller, J. 1985. Der Einfluß der Wirtspflanze auf die Geschlechtsdeterminierung bei Heterodera schachtii. Mitt. Biol. Bundesanst. LandForstwirtsch. Berlin-Dahlem 226:46-63.

Paal, J., Henselewski, H., Muth, J., Meksem, K., Menendez, C. M. Salamini, F., Ballvora, A., and Gebhardt, C. 2004. Molecular cloning of the potato Grol-4 gene conferring resistance to pathotype Rol of the root nematode Globodera rostochiensis, based on a candidate gene approach. Plant J. 38:285-297.

Paulson, R. E., and Webster, J. M. 1972. Ultrastructure of the hypersensitive reaction in roots of tomato, Lycopersicon esculentum $\mathrm{L}$. to infection by the root-knot nematode, Meloidogyne incognita. Physiol. Plant Pathol. 2:227-234.

Phillips, M. S. 1994. Inheritance of resistance to nematodes. Pages 319338 in: Potato Genetics. J. E. Bradshaw and G. R. Mackey, eds. CAB International, Wallingford, U.K.

Phillips, M. S., Forrest, J. M. S., and Farrer, L. A. 1982. Invasion and development of juveniles of Globodera pallida in hybrids of Solanum vernei x S. tuberosum. Ann. Appl. Biol. 100:337-344.

Rice, S. L., Leadbeater, B. S. C., and Stone, A. R. 1985. Changes in cell structure in roots of resistant potatoes parasitized by potato cyst nematodes. I. Potatoes with resistance gene $H_{1}$ derived from Solanum tuberosum ssp. andigena. Physiol. Plant Pathol. 27:219-234.

Roberts, P. A., and Stone, A. R. 1983. Comparisons of invasion and development of Globodera spp. and European potato cyst-nematode pathotypes in roots of resistant Solanum sg. Leptostemonum spp. Nematologica 29:95-108.

Sembdner, G. 1963. Anatomie der Heterodera-rostochiensis-Gallen an Tomatenwurzeln. Nematologica 9:55-64.

Sijmons, P. C., Atkinson, H. J., and Wyss, U. 1994. Parasitic strategies of root nematodes and associated host cell responses. Annu. Rev. Phytopathol. 32:235-259.

Sijmons, P. C., Grundler, F. M. W., von Mende, N., Burrows, P. R., and 
Wyss, U. 1991. Arabidopsis thaliana as a new model host for plantparasitic nematodes. Plant J. 1:245-254.

Turner, S. J., and Stone, A. R. 1984. Development of potato cyst-nematodes in roots of resistant Solanum tuberosum ssp. andigena and $S$. vernei hybrids. Nematologica 30:324-332

van der Vossen, E. A., van der Voort, J. N., Kanyuka, K., Bendahmane, A. Sandbrink, H., Baulcombe, D. C., Bakker, J., Stiekema, W. J., and Klein-Lankhorst, R. M. 2000. Homologues of a single resistance-gene cluster in potato confer resistance to distinct pathogens: A virus and a nematode. Plant J. 23:567-576.

Van Kan, J. A., Cozijnsen, T., Danhash, N., and De Wit, P. J. 1995. Induction of tomato stress protein mRNAs by ethephon, 2,6-dichloroisonicotinic acid and salicylate. Plant Mol. Biol. 27:1205-13.
Vos, P., Simons, G., Jesse, T., Wijbrandi, J., Heinen, L., Hogers, R. Frijters, A., Groenendijk, J., Diergaarde, P., and Reijans, M., FierensOnstenk, J., deBoth, M., Peleman, J., Liharska, T., Hontelez, J., Zabeau, M. 1998. The tomato Mi-1 gene confers resistance to both root-knot nematodes and potato aphids. Nat. Biotechnol. 16:1365-1369.

Williamson, V. M. 1998. Root-knot nematode resistance genes in tomato and their potential for the future. Annu. Rev. Phytopathol. 36:277-293.

Williamson, V. M., and Gleason, C. A. 2003. Plant-nematode interactions. Curr. Opin. Plant Biol. 6:327-33.

Wyss, U., Stender, C., and Lehmann, H. 1984. Ultrastructure of feeding sites of the cyst nematode Heterodera schachtii Schmidt in roots of susceptible and resistant Raphanus sativus L. var. oleiformis Pers. cultivars. Physiol. Plant Pathol. 25:21-37. 